Kansas State University Libraries

New Prairie Press

\title{
NONLINEAR ESTIMATION OF GROWTH CURVE MODELS FOR GERMINATION DATA ANALYSIS
}

\author{
Bahman Shafii \\ William J. Price \\ Jerry B. Swensen \\ Glen A. Murray
}

See next page for additional authors

Follow this and additional works at: https://newprairiepress.org/agstatconference

Part of the Agriculture Commons, and the Applied Statistics Commons

\section{(c) (1) $\Theta(9$}

This work is licensed under a Creative Commons Attribution-Noncommercial-No Derivative Works 4.0 License.

\section{Recommended Citation}

Shafii, Bahman; Price, William J.; Swensen, Jerry B.; and Murray, Glen A. (1991). "NONLINEAR ESTIMATION OF GROWTH CURVE MODELS FOR GERMINATION DATA ANALYSIS," Conference on Applied Statistics in Agriculture. https://doi.org/10.4148/2475-7772.1415

This is brought to you for free and open access by the Conferences at New Prairie Press. It has been accepted for inclusion in Conference on Applied Statistics in Agriculture by an authorized administrator of New Prairie Press. For more information, please contact cads@k-state.edu. 
Author Information

Bahman Shafii, William J. Price, Jerry B. Swensen, and Glen A. Murray 


\title{
NONLINEAR ESTIMATION OF GROWTH CURVE MODELS FOR GERMINATION DATA ANALYSIS
}

\author{
Bahman Shafii and William J. Price, Statistical Programs, \\ Jerry B. Swensen, and Glen A. Murray, Division of Plant Sciences \\ College of Agriculture \\ University of Idaho \\ Moscow, ID 83843
}

\begin{abstract}
Logistic, Gompertz, Richards and Weibull growth curves were evaluated for their suitability as mathematical and empirical models to represent cumulative germination. By avoiding the limitations associated with the method of moments and single-value germination indices, the fitted models provided superior description of the time course of germination. The four-parameter Weibull model gave the best fit across a relatively wide range of seed species and germination conditions, and the resulting parameter estimates reflected identifiable aspects of the germination process. The nonlinear estimation of the germination response included a parameter summary, together with their asymptotic standard errors and correlation matrix, along with an approximate band for the expectation function, pairwise plots of the parameter inference region, and profile $t$ plots. Evaluation of the fitted models also included information on lack of fit and residual structure. Empirical results and hypothesis testing were demonstrated with reference to a replicated experiment designed to determine the effects of reduced water potential on germination of onion seeds.
\end{abstract}

Keywords: nonlinear regression, cumulative germination, growth curves, Weibull model.

\section{INTRODUCTION}

Seed germination is a complex biological process beginning with water uptake by the seed and culminating in emergence of the embryo from the seed coat (radical or hypocotyl emergence). Many researchers have attempted to quantify this process which is influenced by various environmental as well as genetic factors. The effect of specific factors is typically presented in terms of an S-shaped germination curve, relating the cumulative percentage of germination to time. The ideal description of germination should be complete, concise, unambiguous, and amenable to statistical analysis (Brown and Meyer, 1988a). It should also provide information concerning 
location (lag), rates (speed), and extent of germination.

Traditional methods used in germination data analysis include single-value indices and the method of moments. Single-value indices have been used extensively in order to summarize the time course of germination with a few coefficients (germination indices). They have often been utilized to emphasize independent aspects of germination, or enable distinguishing superior germination from inferior germination (e.g. Kotowski, 1926; Macguire, 1962; Timson, 1965; Gordon, 1971; Lehle and Putnam, 1982). Similarly, in the method of moments, statistics such as total, mean, and variance of time to germination, quartiles, percentiles, time to $50 \%$ germination, etc., are used to represent the germination process and assimilate final germination (e.g., Tucker and Wright, 1965; Nichols and Heydecker, 1968; Thompson, 1970; Orchard, 1977).

Limitations associated with moments and indices in describing the germination process are: i) they are insensitive, ambiguous, and incomplete, ii) they do not supply essential information about location, acceleration, dispersion in time, and extent of germination, iii) they assume a normal distribution for the frequency of germination (i.e., method of quantiles, probit analysis, polynomial regression) whereas the frequency distribution of germination time is skewed, and iv) the do not describe the germination process, they simply represent it.

An alternative to using an index number for defining the processes of germination is the use of growth models. Given the correct mathematical specification along with the appropriate statistical estimation, this approach can provide considerable information resulting in parameter estimates with meaningful and relevant biological interpretations. Many mathematical models have been proposed to describe germination curves including (but not limited to) logistic (Janssen, 1973; Hsu, Nelson and Chow, 1984; Torres and Frutos, 1990), Gomphertz (Lapp and Skoropad, 1976; Tipton, 1984), Richards (Berry, Cawood and Flood, 1988), and Weibull (Bonner, and Dell, 1976; Brown and Mayer, 1988b) functions.

The purpose of this study was to evaluate the suitability of the specified growth models to describe germination data using nonlinear regression. Additionally, statistical criteria pertinent to presenting nonlinear estimation results are discussed. Empirical applications are demonstrated using seeds from a wide range of both crop and weed species (onion, rapeseed, sugarbeet, kochia, matgrass, and medusa head) under a variety of germination conditions. Specific references are made to a replicated experiment designed to investigate the effects of reduced water potential on germination behavior of onion seeds.

\section{METHODS}

Four common nonlinear asymptotic growth models were used for evaluation, including two three-parameter and two four-parameter models. These were:

(i) logistic

(ii) Gompertz

$$
\begin{aligned}
& y=M[1+\exp (L-K t)]^{-1} ; \\
& y=M[\exp (-\exp (L-K t))]
\end{aligned}
$$


(iii) Richards

(iv) Weibull

$$
y=M[1-\exp (-K(t-L))]^{1 /(1-C)} ; \text { and }
$$

where

$$
\left.y=M\left[1-\exp (-K(t-L))^{c}\right)\right]
$$

$\mathrm{y}=$ cumulative percentage germination at time $\mathrm{t}$,

$\mathrm{M}=$ asymptote (theoretical maximum for $\mathrm{y}$ ),

$\mathrm{L}=$ time scale (lag related) constant,

$\mathrm{K}=$ rate of increase, and

$\mathrm{C}=$ shape parameter.

The logistic function is sigmoid and symmetrical about the inflection point. This function is very similar to the cumulative normal distribution. (unskewed and perfectly symmetrical). In spite of its popularity however, it can impose a limitation in fitting germination data, since cumulative germination curves are nearly always skewed (Moore and Ross, 1982; Brown and Mayer, 1988b). The Gompertz function is sigmoid and asymmetrical about the inflection point with a fixed skewness of approximately 1.3. Like the logistic, the Gompertz function starts with a lower asymptote, making the estimation of lag time (start of germination) rather arbitrary.

The Richards model is based on a four-parameter sigmoid function, with $\mathrm{C}$, the shape parameter, measuring the various patterns and indicating alternative functional forms (i.e. monomolecular, logistic, Gompertz) that may be generated by this model. While flexible, the function has significant curvature in the solution locus of all four of its parameters (Ratkowsky, 1983), lacks desirable properties associated with the estimated parameters (Ratkowsky, 1990), and demonstrates some degree of nonconvergence in empirical estimation. The Weibull model is a flexible and simple function with great potential for application to biological data, particularly if the system to be modeled can exist in either of two states (e.g., germinated or ungerminated). It is often suitable where conditions of strict randomness of the exponential distribution are not satisfied (Brown, 1987). The Weibull has been used by several authors for analyzing and describing seed germination (Bonner and Dell, 1976; Brown and Mayer, 1988b; Bridges, et al, 1989). The function's parameters are biologically interpretable, reflecting maximum germination $(M)$, germination rate $(K)$, lag in onset of germination (L), and the shape of the cumulative distribution (C).

The estimation of specified growth curve models was accomplished using the univariate nonlinear regression and the Gauss-Newton algorithm. Theoretical developments concerning the iterative estimation procedure and linear approximation along with practical considerations are reviewed by Bard (1971), Gallant (1987), and Bates and Watts (1988). Details of alternative estimation methods are given in Kennedy and Gentle (1980).

Statistical computations were carried out using SAS/STAT,IML (1989, 1985). Program codes required for the Gauss-Newton algorithm, alternative functional forms and their respective derivatives, as well as other statistical criteria presented in this section are given in the Appendix.

Presenting the statistical results of nonlinear estimation, as in all statistical analyses, is an important consideration. Regardless of the specific area of research to 
which they may apply, results from a nonlinear regression analysis should be reported clearly and succinctly to ensure provision of meaningful and valid conclusions. The following statistical criteria may be considered in presenting nonlinear regression results, particularly when analyzing germination growth curves:

(i) Parameter estimates along with parameter approximate standard errors, t-ratios, and corresponding p-values,

(ii) Asymptotic correlation matrix of the parameters,

(iii) RMS/PRESS,

(iv) If the experiment includes replications:

. Lack of fit analysis

. Plot of replication standard deviations vs. replication averages,

(v) Pairwise plots of parameter inference regions and associated marginal intervals,

(vi) Plot of data, fitted expectation function and approximate confidence bands,

(vii) Residual plots,

(viii) If appropriate, results of single and joint hypothesis

testing,

(ix) Profile $t$ plots.

As in linear regression, the assessment of any fitted model should begin with careful consideration of parameter estimates, both in sign and magnitude. Given convergence to reasonable values has been reached, the parameter approximate standard errors and t-ratios must be checked. Insignificant t-ratios must be investigated and if necessary, the model should be modified or refitted deleting the corresponding parameter(s) from the expectation function. The parameter approximate correlation matrix should be checked for excessively high correlation (>.99 in many cases). High correlations indicate overparameterization and a need for either simplifying the expectation function or transforming the variables or parameters to reduce collinearities (Bates and Watts, 1988).

Statistics such as Residual Mean Squares (RMS) and Prediction Sum of Squares (PRESS) help in assessing the overall fit, and if non-nested models are considered may be used to select among candidate models (aside from biological considerations, one might favor the model with the smallest RMS/PRESS and the most random looking residuals).

When the experiment includes replications, tests for Lack of Fit (LOF) of the expectation function may be performed, which involves decomposing the residual sum of squares (SS) with n-p degrees of freedom into replication SS with $r$ degrees of freedom and LOF SS with $n-p-r$ degrees of freedom. The ratio MS(LOF)/MS(Rep) is then compared to the critical value of $F(n-p-r, r ; \alpha)$ to determine the significance of LOF tests. In addition, plot of replication standard deviations against replication averages (even prior to specifying an expectation function) may be used to check for systematic relationships and to determine whether a variance-stabilizing transformation is necessary.

Approximate inference regions for parameters of the nonlinear model

$$
\begin{aligned}
y & =F\left(X_{1}, X_{2}, \ldots, X_{n} ; \theta_{1}, \theta_{2}, \ldots, \theta_{p}\right)+\epsilon \\
& =F(\theta)+\epsilon,
\end{aligned}
$$


is given by

$$
(\theta-\hat{\theta})^{\prime} \hat{\mathbf{V}}^{\prime} \hat{\mathbf{V}}(\theta-\hat{\boldsymbol{\theta}}) \leq \mathrm{ps}^{2} \mathrm{~F}(\mathrm{p}, \mathrm{n}-\mathrm{p} ; \alpha)
$$

where $\mathbf{V}$, the derivative matrix is evaluated at $\hat{\theta}$ (Bates and Watts, 1988). Note that $\hat{\mathbf{V}}=\hat{\mathbf{Q}}_{\mathbf{1}} \hat{\mathbf{R}}_{\mathbf{1}}$ following a $\mathrm{QR}$ decomposition which involves decomposing $\hat{\mathbf{V}}$ into the product of an orthogonal matrix, $\hat{\mathbf{Q}}$ (i.e.: $\hat{\mathbf{Q}}^{\prime} \hat{\mathbf{Q}}=\hat{\mathbf{Q}} \hat{\mathbf{Q}}^{\prime}=\mathrm{D}$ ) and an upper triangular, easily inverted matrix, $\hat{\mathbf{R}}=\left(\begin{array}{c}\hat{\mathbf{R}}_{\mathbf{1}} \\ \mathbf{0}\end{array}\right)$. Hence,

$$
(\theta-\hat{\theta})^{\prime} \hat{\mathbf{R}}_{1}^{\prime} \hat{\mathbf{R}}_{1}(\theta-\hat{\theta}) \leq \mathrm{ps}^{2} \mathrm{~F}(\mathrm{p}, \mathrm{n}-\mathrm{p} ; \alpha)
$$

The inference region associated with parameter values is a disk centered at $\hat{\mathbf{R}}_{1} \hat{\theta}$ on the expectation plane and is an ellipse centered at $\hat{\theta}$ in the parameter space. Plots of parameter inference regions contain least squares estimates of the parameters, marginal intervals and a joint inference region, and could help visualize the direction of correlation between the specified parameters.

Plot of data along with the fitted expectation function and an approximate confidence band, is an excellent way to assess fit. The approximate inference band for the expected response is given by:

$$
f(X, \hat{\theta}) \pm s|| U^{\prime} \hat{\mathbf{R}}^{-1}|| \sqrt{p F(p, n-p ; \alpha)}
$$

where $\mathbf{U}$ is the derivative vector,

$$
\mathbf{U}=\partial \mathrm{f}(\mathbf{X}, \theta) / \partial \theta^{\prime} \mid \hat{\theta}
$$

Plotting of residuals against predicted values and other lurking factors or control variables (e.g. time, in germination analysis) is a simple and effective method of detecting violations of underlying assumptions and highlighting model inadequacies. Given the nonlinear regression model in (1), where disturbances are assumed to have a spherical normal distribution, i.e. $\mathrm{E}(\epsilon)=0 ; \operatorname{var}(\epsilon)=\mathrm{E}\left(\epsilon \epsilon^{\prime}\right)=$ $\sigma^{2} \mathbf{I}$, it is important that residuals are uniformly spread and random looking (around zero) with no detectable trend. Probability plots of the residuals should also be made to verify the normality assumption [see Draper and Smith (1988), Myers (1986), and Bates and Watts (1988) for details].

Results of single and joint hypothesis testing should also be provided, particularly if various biological or environmental factors (treatments) are present in the experiment. This may include results of single and multiple degree of freedom contrasts on parameter estimates as well as curve comparisons.

Let $\mathbf{H}$ and $\theta$ represent the hypothesis (contrast) and parameter vectors, respectively. define the matrix

$$
\mathbf{C}=\left(\mathbf{R}_{1}{ }^{\prime} \mathbf{R}_{1}\right)^{-1}
$$

where $\mathrm{C}$ represents the inverse of the derivative crossproduct matrix. The statistic 


$$
\mathrm{W}=(\mathrm{H} \theta)^{\prime}\left(\mathrm{HCH}^{\prime}\right)^{-1}(\mathrm{H} \theta) / \mathrm{qs}^{2}
$$

follows the $\mathrm{F}$ distribution with $\mathrm{q}$ (numerator) and $\mathrm{n}-\mathrm{p}$ (denominator) degrees of freedom (Gallant, 1987). That is,

$$
\frac{\mathrm{SS}(\text { contrast }) / \mathrm{q}}{\mathrm{SS}(\text { error }) /(\mathrm{n}-\mathrm{p})} \sim \mathrm{F}(\mathrm{q}, \mathrm{n}-\mathrm{p} ; \alpha) .
$$

Note that $\mathrm{q}$ is the number of restrictions on $\theta$ which is the row rank of $\mathbf{H}$.

For a nonlinear model, the profile $\mathrm{t}$ function (Bliss and James, 1966; Bates and Watts, 1988), $\tau\left(\theta_{\mathrm{p}}\right)$, is defined as

$$
\tau\left(\theta_{\mathrm{p}}\right) \doteq \operatorname{sign}\left(\theta_{\mathrm{p}}-\hat{\theta}_{\mathrm{p}}\right) \sqrt{\frac{\mathrm{SS}_{2}-\mathrm{SS}_{1}}{M S_{1}}}
$$

where $\mathrm{SS}_{2}$ is the profile sum of squares ( achieved by constraining an individual parameter to a constant, $\theta_{\mathrm{p}}$, and obtaining least squares estimates for the remaining parameters) and $\mathrm{SS}_{1}$ and $\mathrm{MS}_{1}$ represent the sum of squares and mean square error from the final unconstrained estimation of $\theta$, and $\hat{\theta}_{\mathrm{p}}$ is the unconstrained estimate of the $\mathrm{p}^{\text {th }}$ parameter. The plot of $\tau\left(\theta_{\mathrm{p}}\right)$ versus the studentized parameter,

$$
\delta\left(\theta_{\mathrm{p}}\right)=\left(\theta_{\mathrm{p}}-\hat{\theta}_{\mathrm{p}}\right) / \operatorname{se}\left(\hat{\theta}_{\mathrm{p}}\right),
$$

is called the profile $t$ plot. As curvature measures, profile $t$ plots provide valuable information concerning the nonlinearity of the estimation situation (with respect to each parameter). Additionally, they may be used to determine nominal $100(1-\alpha) \%$ likelihood intervals,

$$
-\mathrm{t}(\mathrm{n}-\mathrm{p} ; \alpha / 2) \leq \tau\left(\theta_{\mathrm{p}}\right) \leq \mathrm{t}(\mathrm{n}-\mathrm{p} ; \alpha / 2)
$$

for individual parameters.

\section{EMPIRICAL RESULTS}

The data used to illustrate the techniques outlined previously were from an experiment to test the effects of reduced water potential on the germination of onion seed. The treatments consisted of 4 water potential levels of $0,-.662,-1.14$, and $1.57 \mathrm{mPa}$ labeled 1 through 4 , respectively, which were applied to seeds of the onion cultivar Challenger. The treated seeds were then incubated at $25 \mathrm{C}$ in light for 20 days. Germination was scored daily as the number of seeds out of 100 showing radicle protrusion greater than $1 \mathrm{~mm}$. The experiment was replicated 8 times.

Summary statistics on the cumulative germination of each of the four treatments are presented in table (1). Mean cumulative germination decreased from 72 to $7 \%$ as water potential decreased from 0 to $-1.57 \mathrm{mPa}$. Skewness became more positive as water potential dropped and variability remained relatively constant except 
at the lowest water potential. This treatment exhibited positive skewness, and decreased variability compared to other treatments. The data implied that this difference was due to truncation and more time ( $>20$ days) would be required to observe final germination at this water potential.

The Weibull model was fitted to the individual treatments using nonlinear estimation as described earlier, and results are presented in table 2 . In each treatment the default convergence criteria of the algorithm was satisfied. All parameter estimates were significantly different from zero based on asymptotic $t$ tests, suggesting the model was reasonable and all parameters were required. Again the lowest water potential treatment was a possible exception with the estimate for the parameter $\mathrm{C}$ being marginally significant $(\mathrm{P}=.10)$.

The differences in parameter estimates between treatments paralleled differences seen in the summary statistics and had biological significance. The maximum attainable germination, estimated by $\mathrm{M}$, decreased as water potential decreased indicating that restricting the availability of water increases the proportion of seeds which are unable to develop sufficient turgor pressure to effect sprouting. The estimates of $\mathrm{K}$, which is related to the rate of germination, also decreased with lowered water potential. Reduced water potential in the solution surrounding the seed decreases the rate at which water is taken up by the seed and may also reduce the rate of various metabolic processes required to accomplish germination. The same biological explanation can be given to changes in the estimates of lag time to initial germination $(\mathrm{L})$, which increased as water potential dropped. Thus the parameter estimates from the Weibull model were consistent with the observed data and had relevant biological interpretations.

The correlational structure of the estimates was consistent in relative magnitude and sign between treatments with no correlations greater than .99 in magnitude. The models did not appear to be overparameterized.

LOF tests found no significant lack of fit in any treatment (lowest $p$ value was .17) indicating that estimated functions intersected the data well. Inaddition, plots of replication standard deviations vs. replication averages were examined for heteroscedasticity within each treatment. There were no unexpected patterns, and thus, transformations or other variance stabilizing procedures were not required.

Residual analyses on each model were also included and showed no problems. Plots of studentized residuals vs. predicted values and time showed the residuals to behave in a random fashion with no unexpected patterns. They were evenly distributed about zero with acceptable magnitudes. Probability plots verified the correctness of the normality assumption.

The $95 \%$ pairwise inference regions for the parameter estimates, given in (2) and (3), as well as approximate $95 \%$ marginal confidence intervals, are shown in Figure 1. Only the first treatment is shown since other treatments produced similar results. The least square estimates are marked as a $(+)$ at the center of each ellipse and the marginal intervals (dashed lines) can be read directly from the plots. The direction of the ellipses also indicates the sign of the correlation between parameter estimates. Although the shape of the ellipses is related to the magnitude of the respective correlations, it is not appropriate to compare ellipses in this case given the differences in scales for each respective plot. 
Figure 2 represents the data from the specified water potential treatments plotted along with their respective Weibull functions and the $95 \%$ inference bands (4). The curves follow the data patterns consistently and individual points do not stray far from their expectation functions. The inference bands follow the curves well with little deviation. This figure clearly demonstrates the effect of decreased water potential on germination and shows the marked difference in germination at the lowest water potential level.

Profile $t$ plots, as described earlier, were prepared for each treatment. However only those for the first treatment are shown here (Figure 3). A straight dashed line at $45^{\circ}$ represents the perfect linear estimation condition. The degree of deviation of the profile sum of squares function (presented as a curved solid line) from this reference is an indicator of the amount of nonlinearity of the actual estimation situation. Although slight curvature was evident in parameter estimates $M$ and $\mathrm{L}$, the overall situation was determined to be satisfactory. The profile $t$ plots for other treatments also showed slight but not severe curvature for some parameters. Profile $t$ plots may also be used for determining exact likelihood intervals for individual parameters. The axes for $\delta$ and tau can be rescaled to units of the parameter and significance levels, respectively. By tracing a line from a given significance level through the profile sum of squares function, the likelihood interval of the parameter can be found. These values can then be compared to the linear approximation of the interval to give an idea of the nonlinearity of the parameter estimation. For example in the first treatment the estimate of the parameter $\mathrm{K}$ was 1.19. The linear approximate $95 \%$ confidence interval was .93 to 1.45 . Using the profile $t$ plot for $\mathrm{K}$, the exact likelihood interval on $\mathrm{K}$ was .94 to 1.49 , which is well approximated by the linear approximate interval. Nonlinearity for all parameters was determined to be slight and reparameterization of the expectation function was unnecessary.

An important aspect of using growth curves to describe germination is the ability to preform single and joint tests of hypotheses (5). Such testing procedures allow for detailed analysis of the germination process. As a case in point, comparisons between the control in this study (treatment 1) and the other treatments were made (Figure 4). A single degree of freedom contrast on the maximum attainable germination was made by comparing the estimate of $\mathrm{M}$ for the control with the average estimate of $\mathrm{M}$ for the other treatments. This test found the treatments to be significantly different than the control in this aspect of germination $(\mathrm{P}<.0001)$. Similarly a multiple degree of freedom contrast of the average estimates of $\mathrm{K}$ and $\mathrm{L}$, gave a 2 degree of freedom test that had marginal significance $(\mathrm{P}=.07)$. Curve comparisons may be done as well. A hypothesis of identical parameters for the control and the average of the other treatments was tested with 4 degrees of freedom and was rejected at $p<.0001$. From these tests it can be inferred that reduced water potential influenced the whole germination process by affecting the number of seeds and, to a lesser degree, the rate at which they germinated. In sum, reduced water potential increased the germination lag, decreased the rate of germination and significantly reduced the final germination.

The other growth models were also tried on this data. Although the Logistic is commonly used in germination studies, it was found to have a significant lack of 
fit. It would seem that the zero skewness characteristic of this model would preclude its use for most germination modelling. The Gompertz fit to the data was marginal. The LOF tests were nonsignificant but the relatively small size of the $p$ values and subsequent residual analysis suggested that this function did not model the process well. The Richards function allows for an adjustable skewness by adding a fourth parameter. However, when fitted to the onion data, the parameter estimates for this model exhibited very large standard errors and high correlations as well. Sensitivity to starting values and extremely long convergence times limited the usefulness of the Richards function. All of the above models had RMS and PRESS values larger than those of the Weibull model. The Weibull model consistently out performed the other models in convergence time, relative magnitudes of standard errors and correlations, and LOF.

Germination data from several crop and weed species were used to assess the Weibull function as a germination model. Seeds of onion, rapeseed, sugarbeet, kochia, matgrass, and medusa head were germinated under a variety of conditions including simulated seed aging, temperature treatments, source of seed, and water potential treatments. In all cases no significant lack of fit was found. Convergence was usually fast and correlations of parameter estimates were reasonable. In a few cases where the convergence was slow or the correlations high, the problem was in part due to insufficient observations between initial and maximum germination. A revised sampling schedule should help remedy this problem. The Weibull model was found to be robust for the description of seed germination over a wide range of species and germination conditions.

\section{CONCLUDNG REMARKS}

Traditional methods used in seed germination data analysis such as germination indices, moments, coefficient of velocity, and probit analysis fail to describe the time course of germination and they are, for the most part, ambiguous and incomplete. An alternative to utilizing moments and indices is the use of growth models and empirically derived curves which allow germination to be described in terms of three or four coefficients, and hence provide information on location, dispersion in time, rates, and extent of germination. The statistical results from nonlinear estimation of the specified growth model should include, aside from the standard regression statistics, information concerning lack of fit, parameter correlation and inference regions, bands for expectation function, residual structure, and nonlinearity of the estimation situation with respect to individual parameters. The modified fourparameter Weibull model provided a good fit across a relatively wide range of seed species and germination conditions, and the resulting parameter estimates reflected identifiable aspects of germination.

\section{ACKNOWLEDGEMENTS}

Contribution from College of Agriculture, University of Idaho, Idaho Agricultural Experiment Station paper number 9102. 


\section{REFERENCES}

Bard, Y. 1974. Nonlinear Parameter Estimation. Academic Press. New York.

Bates, D.M., and D.G. Watts. 1988. Nonlinear Regression Analysis and its Applications. John Wliey and Sons. New York.

Berry, G.J., R.J. Cawood, and R.G. Flood. 1988. Curve fitting of germination data using the Richards function. Plant, Cell, and Environment 11:183-88.

Bliss, C.I., and A.T. James. 1966. Fitting the rectangular hyperbola. Biometrics. 22:573-602.

Bould, A., and B.K. Abrol. 1981. A model for seed germination curves. Seed Sci. \& Technol. 9:601-11.

Bonner, F.T., and T.R. Dell. 1976. The Weibull function: A new method of comparing seed vigor. J. Seed Technol. 1:96-103.

Bridges, D.C., H. Wu, P.J. Sharpe, and J.M. Chandler. 1989. Modeling distributions of crop and weed seed germination time. Weed Science. 37:724-729.

Brown, R.F. 1987. Germination of Aristida armata under constant and alternating temperatures and its analysis with the cumulative Weibull distribution as a model. Aus. J. Bot. 35:581-91.

Brown, R.F., and D.G. Mayer. 1988. Representing cumulative germination. 2. The use of the Weibull and other empirically derived curves. Ann. Bot. 61:127-38.

Draper, N.R. and H. Smith. 1981. Applied Regression Analysis. 2nd Ed. John Wiley and Sons. New York.

Gallant, A.R. 1987. Nonlinear Statistical Models. John Wiley and Sons, New York.

Gordon, A.G. 1971. The germination resistance test - A new test for measuring germination quality of cereals. Can. J. Plant Sci. 51: 181-83.

Hartley, H.O. 1961. The modified Gauss-Newton method for the Fitting of nonlinear regression functions by least squares. Technometrics. 3:26980.

Hsu, F.H., C.J. Nelson, and W.S. Chow. 1984. A mathematical model to utilize the logistic function in germination and seedling growth. J. Expl. Bot. 351: 1629-40. 
Janssen, J.G.M. 1973. A method of recording germination curves. Ann. Bot. 37: 705-8.

Kennedy, Jr., W.J., and J.E. Gentle. 1980. Statistical Computing. Marcel Dekker Inc. New York.

Kotowski, F. 1926. Temperature relations to germination of vegetable seeds. Amer. Soc. Hort. Sci. Proc. 23: 176-84.

Lapp, M.S., and W.P. Skoropad. 1976. A mathematical model of conidial germination and appressorial formation for Collitotrichum graminicola. Can. J. Bot. 54: 2234-42.

Lehle, F.R., and A.R. Putnam. 1982. Quantification of allicopathic potential of sorghum residues by novel indexing of Richards function fitted to cumulative Cress seed germination curves. Plant Phys. 69: 1212-16.

Maguire, J.D. 1962. Speed in germination - Aid in selection and evaluation for seedling emergence and vigor. Crop Sci. 2: 176-7.

Moore, F.D. and E.E Ross. 1982. Determining differences of viability low rates during seed storage. Seed Sci. Technol. 10:283-300.

Myers, R.H. 1986. Classical and Modern Regression with Applications. Duxbury Press. Boston.

Nicholls, M.A., and W. Heydecker. 1968. Two approaches to the study of germination data. Intl. Seed Test Assn. 33: 531-40.

Orchard, T.J. 1977. Estimating the parameters of plant seedling emergence. Seed Sci. Technol. 5: 61-69.

Ratkowsky, D.A. 1983. Nonlinear Regression Modeling: A Unified Practical Approach. Marcel Dekker, Inc., New York.

Ratkowsky, D.A. 1990. Handbook of Nonlinear Regression Models. Marcell Dekker, Inc., New York.

SAS. 1985. SAS User's Guide: IML. Statistical Analysis System Institute Inc., Cary, NC.

SAS. 1989. SAS User's Guide: Statistics. Statistical Analysis System Institute Inc., Cary, NC.

Thompson, P.A. 1970. Characterization of the germination response to temperature of species and ecotypes. Nature 225: 827-31. 
Timson, J., 1965. New method of recording germination data. Nature 207: 21617.

Tipton, J.L. 1984. Evaluation of three growth curve models for germination data analysis. J. Amer. Soc. Hort. Sci. 4: 451-54.

Torres, M., and G. Frutes. 1990. Logistic function analysis of germination behavior of aged fennel seeds. Enviro. Expl. Bot. 30: 383-90.

Tucker, H., and L.N. Wright. 1965. Estimating rapidity of germination. Crop Sci. 5: 398-9. 


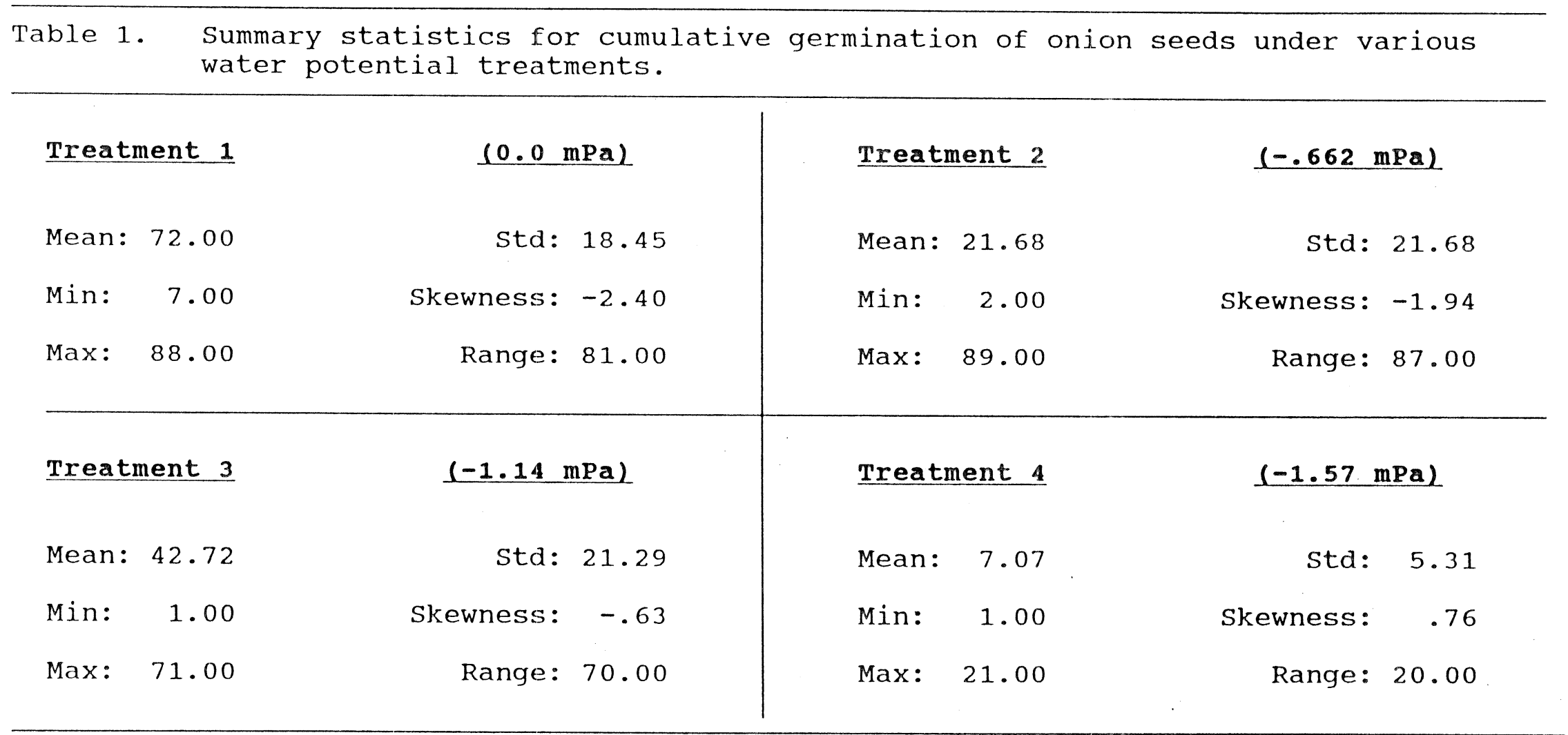


Table 2. Parameter summaries for the weibull function fitted to the onion data.

\section{Treatment 1}

\begin{tabular}{|c|c|c|c|c|c|c|c|c|}
\hline Par. & Est. & s.e. & $\begin{array}{l}\text { App } \\
t\end{array}$ & $\begin{array}{r}\mathrm{P} . \\
\mathrm{P}\end{array}$ & \multicolumn{4}{|c|}{$\begin{array}{c}\text { Correlation } \\
\text { Matrix }\end{array}$} \\
\hline M & 85.25 & 2.20 & 38.9 & 0.0 & 1.00 & & & \\
\hline $\mathrm{K}$ & 1.19 & .13 & 9.2 & 0.0 & -.21 & 1.00 & & \\
\hline L & 1.95 & .01 & 198 & 0.0 & .74 & .33 & 1.00 & \\
\hline C & .45 & .07 & 6.6 & 0.0 & -.87 & -.33 & -.91 & 1.00 \\
\hline $\begin{array}{l}\text { RMS : } \\
\text { PRES }\end{array}$ & s: $\begin{array}{l}21 . \\
271\end{array}$ & & & . & & & & \\
\hline
\end{tabular}

Treatment 3

\begin{tabular}{|c|c|c|c|c|c|c|c|c|}
\hline Par. & Est. & s.e. & $\begin{array}{l}\text { App } \\
t\end{array}$ & $\begin{array}{l}\text { ox. } \\
\mathrm{P}\end{array}$ & \multicolumn{4}{|c|}{$\begin{array}{c}\text { Correlation } \\
\text { Matrix }\end{array}$} \\
\hline M & 63.28 & 2.90 & 21.8 & 0.0 & 1.00 & & & \\
\hline K & .27 & .05 & 5.4 & 0.0 & .03 & 1.00 & & \\
\hline L & 4.39 & .61 & 7.0 & 0.0 & .45 & .57 & 1.00 & \\
\hline $\mathrm{C}$ & 1.24 & .34 & 3.8 & 0.0 & -.65 & -.70 & -.91 & 1.00 \\
\hline $\begin{array}{l}\text { RMS } \\
\text { PRE }\end{array}$ & $\begin{array}{l}62 \\
: \quad 694\end{array}$ & & & & & & & \\
\hline
\end{tabular}

\section{Treatment 2}

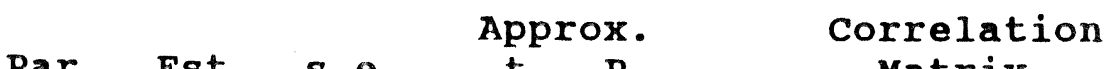
Matrix

$$
\begin{aligned}
& \text { M } \quad 81.84 \quad .92 \quad 89.0 \quad 0.0 \quad 1.00 \\
& \begin{array}{llllllll}
\mathrm{K} & .54 & .04 & 13.5 & 0.0 & -.04 & 1.00
\end{array} \\
& \text { L } \quad 2.82 \quad .09 \quad 21.3 \quad 0.0 \quad .32 \quad .80 \quad 1.00 \\
& \begin{array}{llllllllll}
C & 1.06 & .12 & 8.8 & 0.0 & -.53 & -.84 & -.78 & 1.00
\end{array} \\
& \text { RMS : } \quad 30.2 \\
& \text { PRESS: } 4049.1
\end{aligned}
$$

\section{Treatment 4}

Par. Est. s.e. At

$$
\text { M } \quad 10.97 \quad 1.70 \quad 6.5 \quad 0.0 \quad 1.00
$$

$\begin{array}{llllllll}\mathrm{K} & & .18 & .08 & 2.3 & .01 & -.02 & 1.00\end{array}$

L $\quad \begin{array}{llllllll}6.15 & 2.40 & 2.6 & 0.0 & .43 & .88 & 1.00\end{array}$

C $\quad 1.52 \quad 1.20 \quad 1.3 \quad .10 \quad-.58 \quad-.72 \quad-.93 \quad 1.00$

RMS : $\quad 12.4$

PRESS : 1647.4 
Figure 1. Pairwise plots of the parameter approximate $95 \%$ joint inference regions (solid lines), approximate $95 \%$ marginal confidence intervals (dashed lines) and least squares estimates $(+)$ for the onion data.

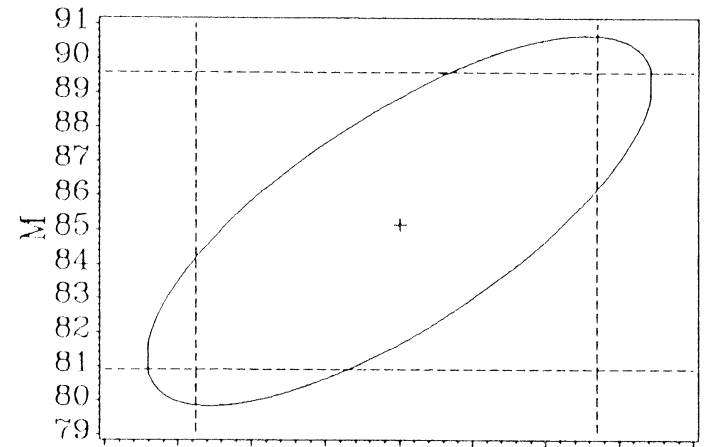

1.941 .951 .961 .971 .981 .992 .002 .012 .02

$\mathrm{L}$

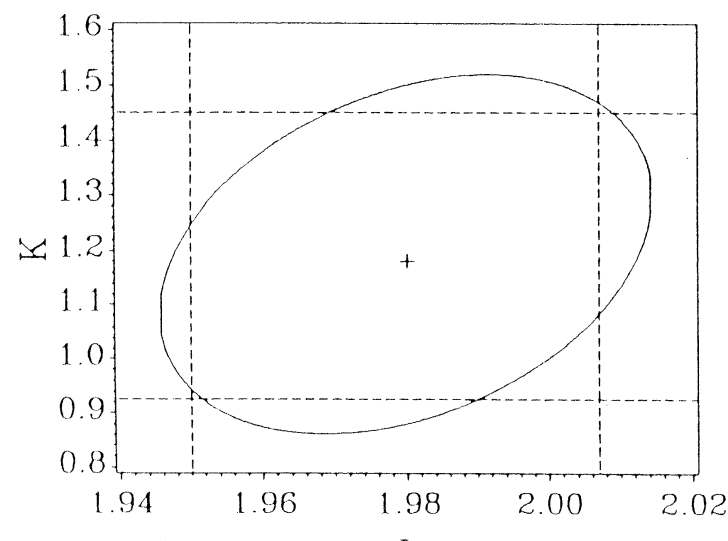

L.
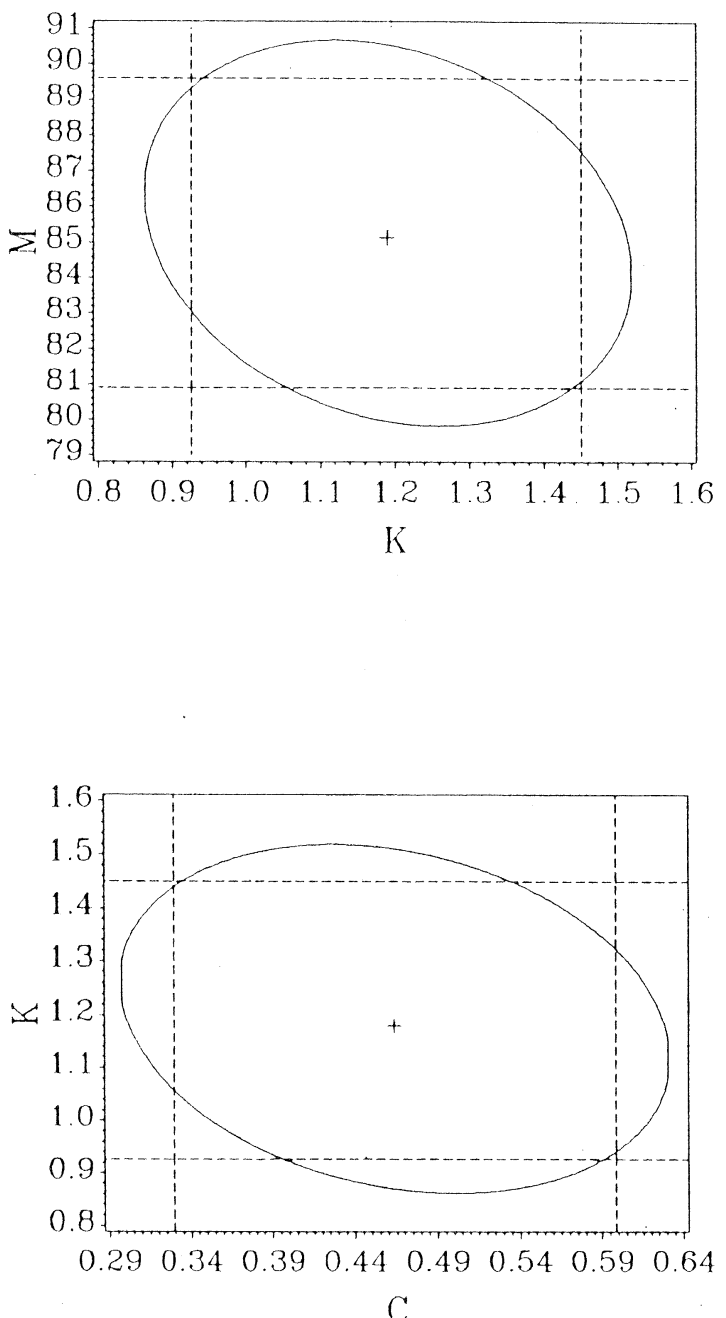
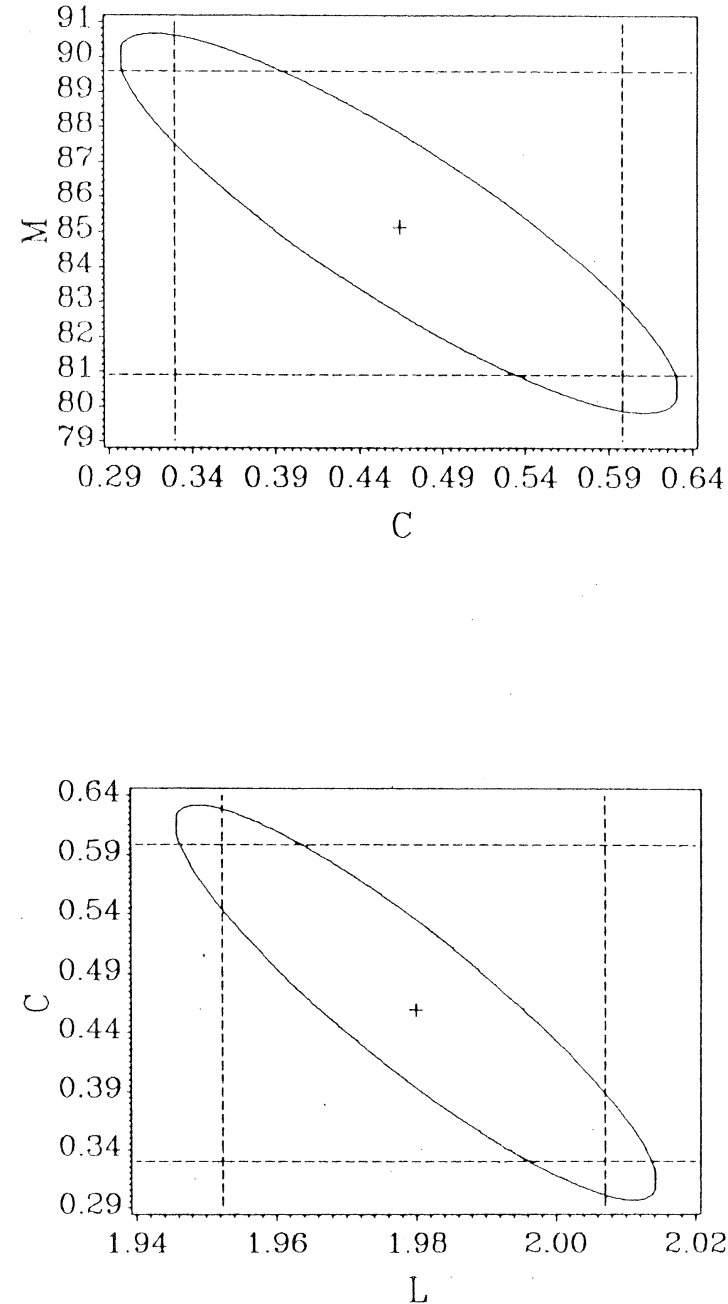
Figure 2. Observed and predicted (solid lines) values of \% cumulative germination for the onion data along with the approximate $95 \%$ confidence bands (dashed lines).
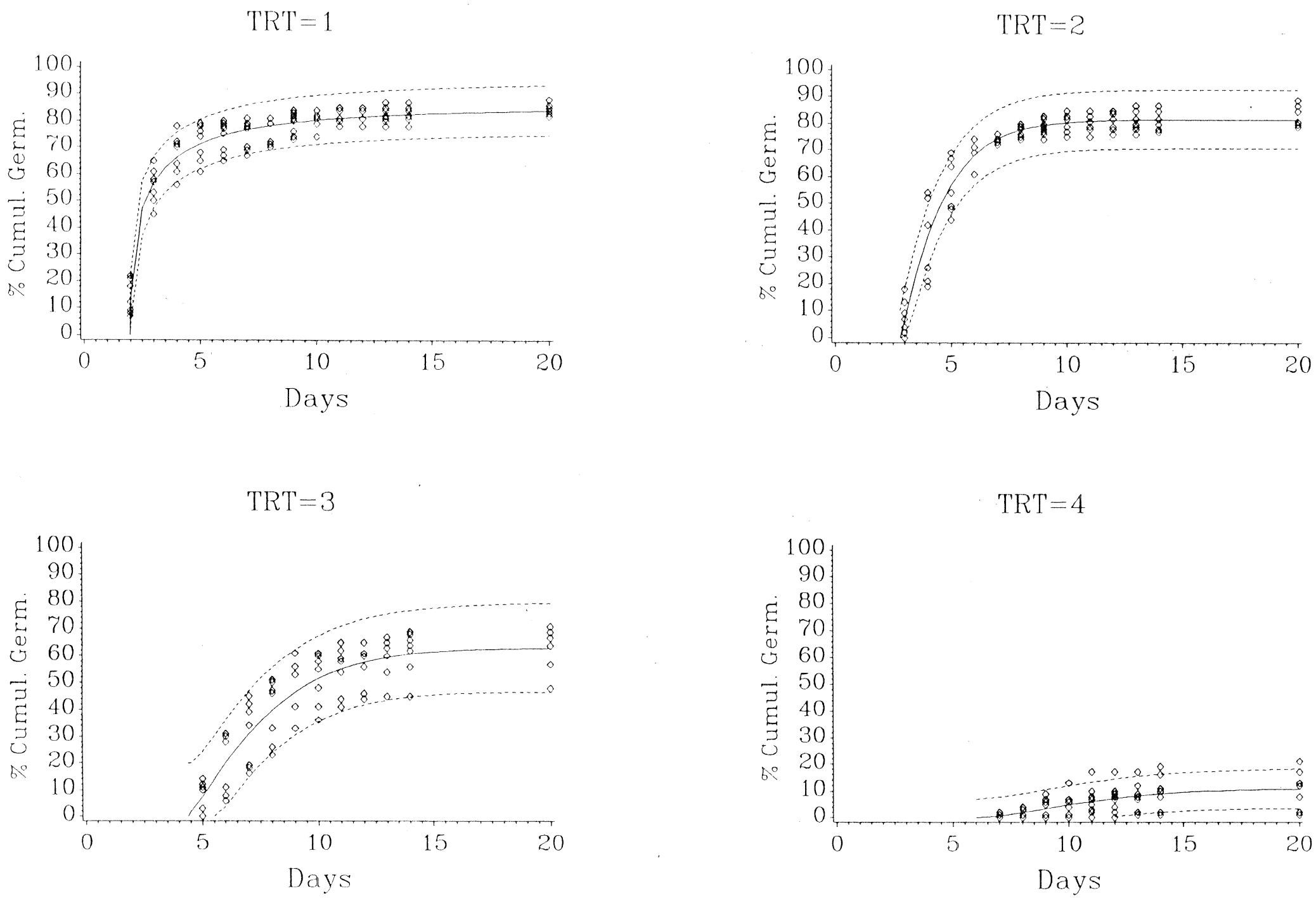
Figure 3. Profile t plots for the parameters of the Weibull model fitted to the onion data (treatment 1). The solid line represents the profile $t$, the dotted line is the linear approximation and the dashed line is the $95 \%$ marginal likelihood interval.
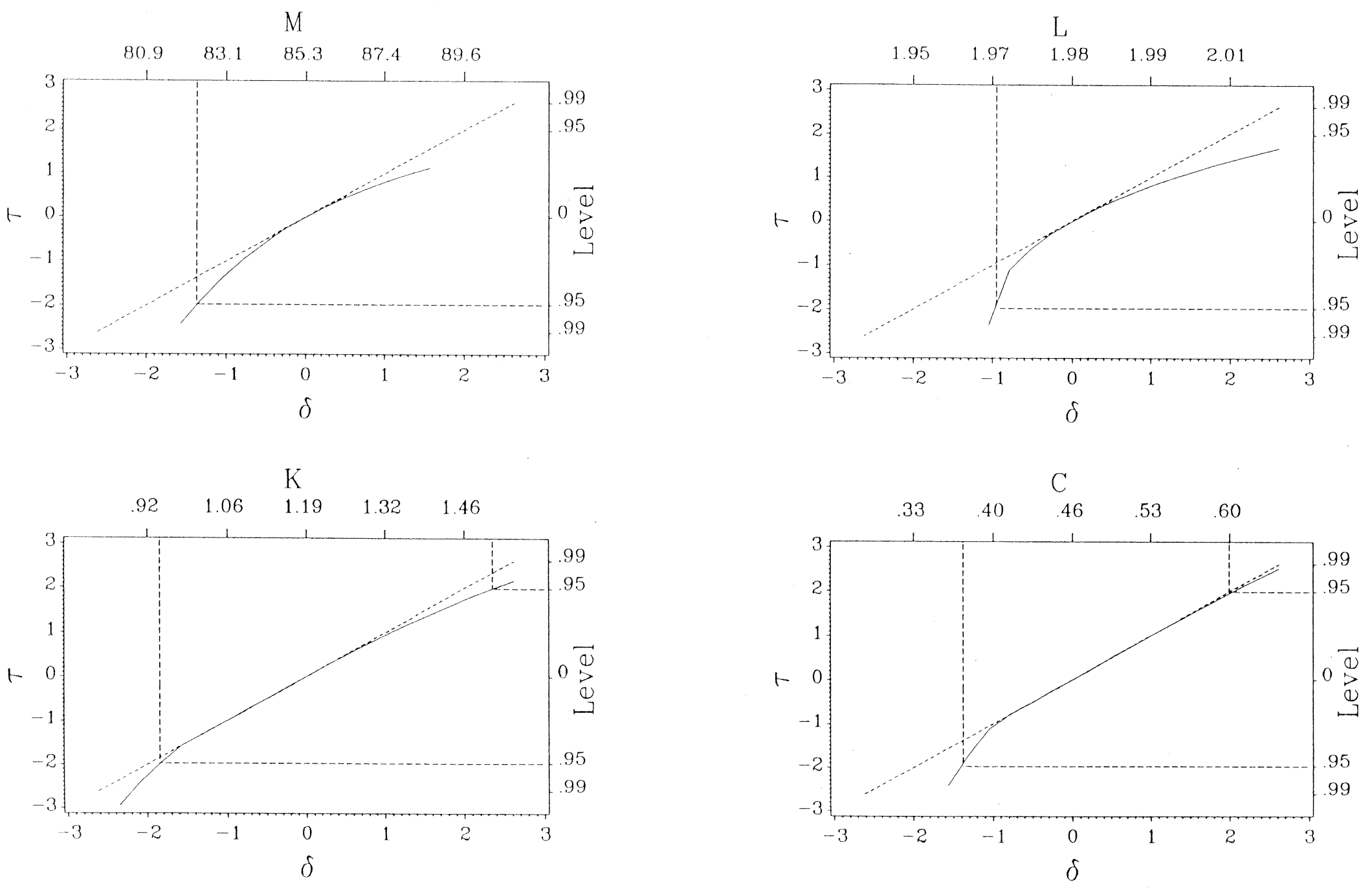
Figure 4. Predicted \% culmulative germination from the Weibull model for the specified onion seed treatments.

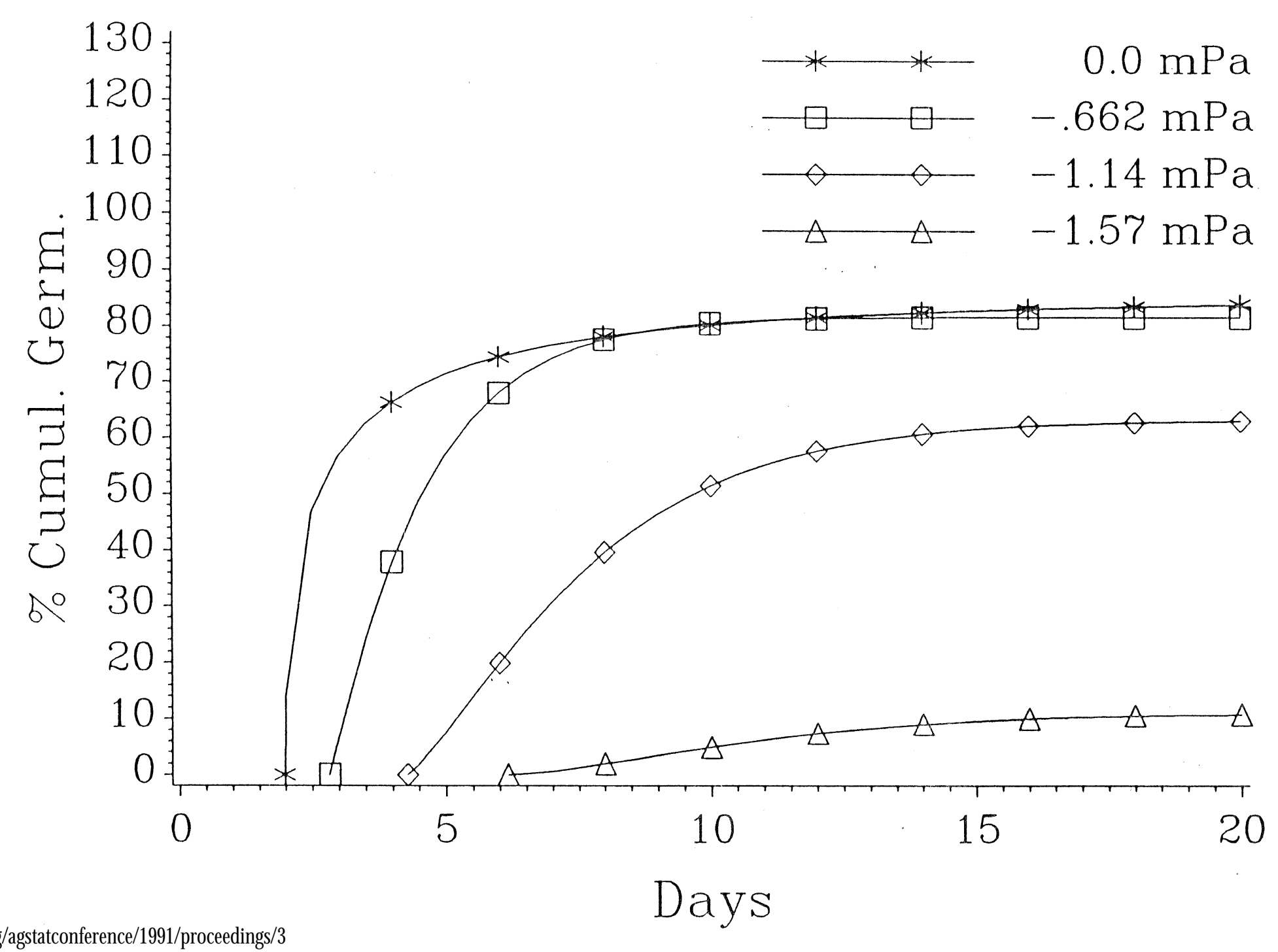




\section{APPENDIX}

\section{SAS/IML Codes for Gauss-Newton Algorithm}

/* GAUSS-NEWTON ALGORITHM (HARTIEY, 1961) ADAPTED FROM BATES AND WATTS (1988) TO READ EXTERNAL DATA, USE WEIBULL FUNCTION, AND CALCULATE S. E'S AND STUDENTIZED RESIDUAIS.

DATA ONION (KEEP = TRT X GERM):

INFILE 'C:IONION.DAT' FIRSTOBS $=6$;

INPUT OBS VAR $\$$ TRT $X$ GERM

IF TRT $=0$ AND VAR $={ }^{\prime} C^{\prime}$;

IF GERM $=0$ THEN DELETE; PROC IML;

START MODEL(THETA, $X, Y$, RES, GRAD, DERIVS); IF $\operatorname{THETA}(|1,1|)>=100$ THEN THETA $(|1,1|)=100$;

IF THETA $(|2,1|)<=0$ THEN THETA $(|2,1|)=0.00001$

IF THETA $(|2,1|)>=2$ THEN THETA $(|2,1|)=1.9999$;

IF $\operatorname{THETA}(|3,1|)<=0$ THEN THETA $(|3,1|)=0.00001$;

IF THETA $(|4,1|)<=0$ THEN THETA $(|4,1|)=0.00001$

TEMP $=\operatorname{EXP}(-(\operatorname{THETA}(|3,1|) *(X-\operatorname{THETA}(|2,1|)))$ \#\#THETA $(|4,1|))$;

YHAT $=$ THETA $(|1,1|) *(1-$ TEMP $)$

RES $=\mathrm{Y}-$ YHAT;

IF DERIVS $=1$ THEN DO:

DER $M=1-$ TEMP:

DER_L $=-\operatorname{THETA}(|1,1|)^{*} \operatorname{THETA}(|3,1|)$ * THETA $(|4,1|) *$ TEMP $n(($ THETA $(|3,1|)$ *(X-THETA $(|2,1|)))$

\#(THETA $(|4,1|)-1))$;

DER_K $=$ THETA $(|1,1|)^{*} \operatorname{THETA}(|4,1|)^{*}$

(TEMPH(X-THETA $(|2,1|)$

"((THETA $(|3,1|) *(X-$ THETA $(|2,1|)))$ H(THETA $(|4,1|)-1)))$ :

DER_C $=$ THETA $(|1,1|) *$ TEMPNLOG(THETA $(|3,1|)$

*(X-THETA $(|2,1|))) *($ THETA $(|3,1|)$

*(X-THETA $(|2,1|)))$ **THETA $(|4,1|)$;

GRAD = DER M $\mid$ DER L || DER K || DER C; END; FINISH;

New Prairie Press

https://newprairiepress.org/agstatconference/1991/proceedings/3
$1 *$ CHECK BOUNDS */

$1 *$

* parameters.

* calculate

Y HAT AND

RESIDUALS.

evaluate

DeRIVATtVe

AND PUT IN

vector

GRAD

IF DERIVS $=1$.
$1 *$

START NLSFTT(THETA, DAYS, Y, YHAT, CRITERION, MAXITER, MINSTEP, TOL, VERBOSE);

RUN MODELTHETA, DAYS, Y, RESID, GRAD, 1);

$P=\operatorname{NROW}($ THETA)

$\mathrm{N}=\operatorname{NROW}(\mathrm{RESID})$

$\mathrm{NDOF}=\mathrm{N}-\mathrm{P}$

MULT $=S Q R T(N D O F / P)$

STEPSIZE $=1$

DO ITER $=1$ TO MAXITER

OLDSSQ = SSQ(RESID);

CALL GSORTH(QHAT RHAT RANK,GRAD):

IF RANK $=1$ THEN DO;

PRINT "SINGULAR DERIVATIVE MATRIX" STOP;

END;

TAN $=$ QHAT $^{*}$ RESID

SS TAN $=$ SSQ(TAN):

INCR = SOLVE(RHAT TAN):

CRITERION = MULT * SQRT(SS TAN/(OLDSSQ SS_TAN));

IF VERBOSE THEN

PRINT ITER (|FORMAT $=2.0 \mid$ )

CRITERION (INCR');

IF CRITERION < TOL THEN LINK DOMORE:

DO UNTTL (NEWSSQ $<$ OLDSSQ);

IF STEPSIZE < MINSTEP THEN DO

PRINT - STEP FACTOR REDUCED BELOW MINIMUM":

$$
\text { STOP; }
$$

END;

TRIAL $=$ THETA + STEPSIZE * INCR

RUN MODEL(TRIAL, DAYS, Y, RESID, GRAD, 0 );

NEWSSQ $=$ SSO(RESID);

IF VERBOSE THEN

PRINT STEPSIZE NEWSSQ (TRIAL')

END

STEPSIZE $=$ STEPSIZE $/ 2$;

THETA $=$ TRIAL

$\begin{array}{lll}\text { /* GET } & * / \\ \text { /* DERIVATIVES } & * / \\ \text { /* AND RESIDUALS. } * / \\ \text { /* SET UP FOR }\end{array}$


STEPSIZE $=\operatorname{MIN}(1 / 14 *$ STEPSIZE

RUN MODELCTHETA,DAYS, Y, RESID,GRAD, 1): ENI);

PRINT "MAXIMUM ITERATIONS REACHED : PROGRAM TERMINATED":

STOP;

DOMORE:

$\mathrm{RI}=\mathrm{INV}(\mathrm{RHAT})$

$\mathrm{S}=$ SQRT(NEWSSQ/NDOF):

$\mathrm{SE}=\mathrm{J}(\mathrm{P}, 1,0)$;

DO I = 1 TO P;

$$
\text { END; }
$$

THETA $=$ THETA ||$S E ;$

$\operatorname{TEMP}^{\prime}=\operatorname{EXP}\left(-\left(\operatorname{THETA}(|3,1|)^{*}(\right.\right.$ DAYS $\left.-\operatorname{THETA}(|2,1|))\right)$ \#\#THETA(|4,1|))

YHAT $=\operatorname{THETA}(|1,1|)^{*}(1-$ TEMP);

YHAT $=$ YHAT ||$R E S I D /(S * S Q R T(1-$ FINISH;

VECDIAG(QHAT*QHAT')));

USE ONION VAR $X X$ GERM $\}$;

READ ALL VAR $\{X\}$ INTO DAYS;

READ ALI, VAR\{GERM\} INTO Y;

THETA $=\{100, .99, .5, .5\}$;

RUN NISFTT(THETA, DAYS, Y, YHAT,

CRITERION, 50, .001, .001, 1);

RESET NAME:

PRINT THETA.YHAT;

RUN

\section{SAS Codes for the Functional Forms}

PROC NLIN METHOD $=$ GAUSS BEST $=1$ DATA $=$ ONION

PARMS $\mathrm{M}=88 \mathrm{~K}=.5 \mathrm{~L}=.99 \mathrm{C}=.5$;

BOUNDS $85<=\mathrm{M}<=88, \mathrm{~K}>0, \mathrm{~L}>0,0<\mathrm{C}<3$.

TEMP1 $=\mathrm{X}-\mathrm{L}$;

TEMP $=\operatorname{EXP}\left(-\left(\left(\mathrm{K}^{*}(\mathrm{TEMP} 1)\right){ }^{* *} \mathrm{C}\right)\right)$;

MODEL GERM $=\mathrm{M}^{*}(1-\mathrm{TEMP})$;

DER. $M=(1-$ TEMP $)$;

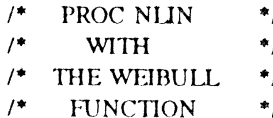

DER. $\mathrm{K}=\left(\mathrm{M}^{*} \mathrm{C}\right)^{*}$ TEMP* $\left(\left(\mathrm{K}^{*}(\mathrm{TEMP} 1)\right)^{* *}(\mathrm{C}-1)\right)^{*}(\mathrm{TEMP} 1)$

DER. $\mathrm{L}=\left(-\mathrm{M}^{*} \mathrm{C}^{*} \mathrm{~K}\right) *$ TEMP**$\left(\left(\mathrm{K}^{*}(\mathrm{TEMP} 1)\right)^{* *}(\mathrm{C}-1)\right)$;

DER.C $=(M)^{*}$ TEMP* $\left(\text { LOG }\left(\left(\mathrm{K}^{*}(\text { TEMP1 } 1)\right)\right)\right)^{*}\left(\mathrm{~K}^{*}(\text { TEMP1 })\right)^{* *} \mathrm{C}$;

OUTPUT OUT $=\mathrm{PRED} 1 \mathrm{P}=\mathrm{PR}$;

TITIEI 'NON IINEAR FIT TO ONION DATA'

TITLE2 'MODEL: WEIBULL';

PROC NUN METHOD $=$ GAUSS BEST $=1$ DATA $=$ ONION:

PARMS M $=1 \mathrm{~K}=.06 \mathrm{~L}=22 \mathrm{C}=2.01$

BOUNDS $0<\mathrm{M}<=1,0.01<=\mathrm{K}<=.1,20<=\mathrm{L}<=30,2.01<\mathrm{C}<2.3$

TEMP1 $=\left(1-\operatorname{EXP}\left(\mathrm{K}^{*} \mathrm{~L}-\mathrm{K}^{*} \mathrm{X}\right)\right)$

TEMP2 $=(1 /(1-\mathrm{C}))$

TEMP3 = TEMP1;

MODEL $Y=M^{*}((T E M P 1) *$ TEMP $)$

DER. $M=($ TEMP1 $) * *$ TEMP

DER. $\mathrm{K}=\left(-\mathrm{M}^{*}(\mathrm{~L}-\mathrm{X}) /(1-\mathrm{C})\right)^{*}\left(\mathrm{TEMP} 1^{* *}\left(\mathrm{TEMP}{ }^{*} \mathrm{C}\right)\right)^{*}(1-\mathrm{TEMP} 1)$

DER. $\mathrm{L}=\left(-\mathrm{M}^{*} \mathrm{~K} /(1-\mathrm{C})\right)^{*}\left(\mathrm{TEMP1}{ }^{* *}\left(\mathrm{TEMP}{ }^{*} \mathrm{C}\right)\right)^{*}(1-\mathrm{TEMP} 1)$;

DER.C $=\left(\mathrm{M} /\left((1-\mathrm{C})^{* *} 2\right)\right)^{*}\left(\text { TEMP1 }{ }^{* *} \text { TEMP2 }\right)^{*}($ LOG $($ TEMP3 $))$

OUTPUT OUT $=$ PRED1 $\mathrm{P}=\mathrm{PR}$;

TTTLE1 'NON LINEAR FIT TO ONION DATA'

TITLE2 'MODEL: RICHARDS $(\mathrm{C}<1)$ ';

PROC NLIN BEST $=1$ DATA $=$ ONION METHOD $=$ GAUSS;

PARMS $\mathrm{M}=100 \mathrm{B0}=2.5 \mathrm{B1}=1$;

MODEL GERM $=\mathrm{M} /\left(1+\mathrm{EXP}\left(-\mathrm{B} 1{ }^{*} \mathrm{X}+\mathrm{B} 0\right)\right)$;

DER.M $=1 /\left(1+\operatorname{EXP}\left(-B 1^{*} X+B 0\right)\right)$

DER. B0 $=-\operatorname{EXP}\left(B 0-B 1^{*} \mathrm{X}\right)^{*} \mathrm{M} /\left(\left(1+\mathrm{EXP}\left(\mathrm{B} 0-\mathrm{B} 1^{*} \mathrm{X}\right)\right)^{* *} 2\right)$;

(1)

OUTPUT OUT $=$ PRED $1 \mathrm{P}=\mathrm{PR}$ :

TTTLEI 'NON UINEAR FTT TO ONION DATA';

TITLE2 'MODEL: LOGISTIC';

PROC NIIN DATA $=$ ONION METHOD = GAUSS;

PARMS $\mathrm{M}=100 \mathrm{~B}=2.5 \mathrm{~K}=5$;

MODEL GERM $=\mathrm{M}^{*}\left(\operatorname{EXP}\left(-\operatorname{EXP}\left(-\mathrm{K}^{*} \mathrm{X}+\mathrm{B}\right)\right)\right)$;

DER.M $=\left(\operatorname{EXP}\left(-\operatorname{EXP}\left(-\mathrm{K}^{*} \mathrm{X}+\mathrm{B}\right)\right)\right)$

DER. $K=M^{*} X^{*}\left(\operatorname{EXP}\left(\left(-\operatorname{EXP}\left(-K^{*} X+B\right)\right)-K^{*} X+B\right)\right)$;

DER. $B=-M^{*}\left(\operatorname{EXP}\left(\left(-\operatorname{EXP}\left(-K^{*} X+B\right)\right)-K^{*} X+B\right)\right)$;

OUTPUT OUT $=$ PRED1 $P=P R$;

1* PROC NLIN */

1* WITH

$1 *$ THE RICHARD'S *

/* FUNCTION

TITLE1 'NON LINEAR FIT TO ONION DATA':

$\begin{array}{lll}* & \text { PROC NLIN } & * \\ \text { /* } & \text { WITH } & * \\ \text { /* THE LOGISTIC } & * / \\ / * & \text { FUNCTION }\end{array}$

TTTLE2 'MODEL: GOMPHERTZ' 


\section{SAS/IML Codes for Parameter Inference Region}

PROC IML;
GOPTIONS DEV $=$ PS2EGA

IJHNAME PERM 'D. 1 '

कLET $\mathrm{P} 1=\mathrm{C}$;

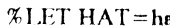

DATA ONION $($ KEEP $=\mathrm{X})$

INFILE 'C:INIJNIONIONIONREP1. DAT' FIRSTOBS $=5$;

$$
\begin{aligned}
& \text { INPUT REP VAR } \$ \text { TRT } X \text { GERM: } \\
& \text { IF TRT }=0 \text { AND VAR }=\text { 'C'; } \\
& \text { IF GERM }=0 \text { THEN DELETE; }
\end{aligned}
$$

START VBYV(X, HVVH, T); $\operatorname{TEMP}=\operatorname{EXP}\left(-\left(T(|3,1|)^{*}(X-T(|2,1|))\right) * \pi T(|4,1|)\right) ;$

DER $M=1$ - TEMP;

DER_L $\mathrm{L}_{-}=-\mathrm{T}(|1,1|)^{*} \mathrm{~T}(|3,1|) * \mathrm{~T}(|4,1|)$

*TEMP \# $((\mathrm{T}(|3,1|) *(\mathrm{X}-\mathrm{T}(|2,1|)))$

$\# \#(\mathrm{~T}(|4,1|)-1))$;

DER $\mathrm{K}=\mathrm{T}(|1,1|)^{*} \mathrm{~T}(|4,1|)^{*}(\operatorname{TEMP} *(\mathrm{X}-\mathrm{T}(|2,1|))$ $*((\mathrm{~T}(|3,1|) *(\mathrm{X}-\mathrm{T}(|2,1|)))$

1* POINTS $1,2,3 \& 4$

* MUST BE CHANGED

* For each param. pair

* POINT \# (1)

* SET PARAM ID's For

* THE PAIR BEING RUN

$*$

* GET DATA TO BE RUN. $\# \#(T(|4,1|)-1)))$; $\#\left(\mathrm{~T}(|3,1|)^{*}(\mathrm{X}-\mathrm{T}(|2,1|))\right) * \| \mathrm{T}(|4,1|)$

GRAD $=$ DER M || DER L || DER K || DER $C$; $G R A D=I N V(G R A D * G R A D)$

$\mathrm{HVVH}=\operatorname{INV}((\operatorname{GRAD}(|2,2|)|| \operatorname{GRAD}(|2,4|))$ //(GRAD(|2,4|)||GRAD $(|4,4|)))$;

FREE DER M DER_L DER K DER C X GRAD; FNISH;

USE ONION;

READ ALL VAR\{X\} INTO TIME;

THETA $=\{85.25,1.98,1.19, .464\}$

RUN VBYV(TIME, HVVH, THETA)
* MODULF CALC'S THE

* DERIVATIVE CROSS

* PRODUCTS MATRIX V

${ }^{*}=$ INV(GRAD*GRAD).

* MATRIX IS SETUP AS:

** X11 X12 X13 X14

* $\times 12 \times 22 \times 23 \times 24$

$V^{*} \times 14 \times 24 \quad \times 34 \quad \times 44$

* WHERE $\mathrm{M}=1, \mathrm{~L}=2, \mathrm{~K}=3$

* AND C $=4$.

1* POINT \# (2)

* ELEMENTS OF V'V THA

* ARE NEEDED ARE PUT

/* IN HVVH. c.g. L.C.

/* END MOdUle.

1* GET DATA AND PUT X

* INTO VECTOR TIME

* DEFINE THETA AS

* (M, L, K, AND C)

1* CALL CROSS PROD'S.
$\mathrm{VPV}=\mathrm{J}(1,3,1)$;

$\operatorname{VPV}(|1,1|)=\operatorname{HVVH}(|1,1|)$;

$\operatorname{VPV}(|1,2|)=\operatorname{HVVH}(|1,2|)$

$\operatorname{VPV}(|1,3|)=\operatorname{HVVH}(|2,2|)$;

CRFATE CROSS FROM VPV

APPEND FROM VPV;

PUT THE EIEMENTS O

* HVVH INTO VECTOR

1* FOR OUTPUT

* outPut to Dataset.

DATA UPPER $(\mathrm{KEEP}=\& \mathrm{P} 1$ \&P2) LOWFR(KEEP $=\& \mathrm{P} 1 \& \mathrm{P} 2) \cdot /^{*}$ DATA STEP CALC'S TH

SET CROSS;

* ELUJPSE IN TWO PARTS

* FOR EASIER PLOTTING.

* i IS THE PARAM TO

- BE ON HORZ. AXIS

* J IS THE VERT. AXIS

* SEE (2)

* SET PARAM EST'S AT

* Final Values also

* MSE AND F(2,N-P:.05)

Lhat $=1.98$;

Khat $=1.19$;

Chat $=.464$;

$\mathrm{MSE}=21.27$

$\mathrm{F}=3.05$

LOLM $=$ \&P2\&HAT - SQRT $\left(\left(\mathrm{Vij}^{*} 2^{*} \mathrm{MSE}^{*} \mathrm{~F}\right) /\right.$ $\left.\left(\left(\mathrm{Vij}^{* *} 2-\mathrm{V}_{\mathrm{jj}} \mathrm{V}_{\mathrm{ii}}\right)^{*}\left(1 / \mathrm{V}_{\mathrm{ij}}^{* *} 2-1\right)\right)\right)$;

UPLM $=\&$ P2\&HAT $+S Q R T\left(\left(V_{i j}^{*} 2^{*} M S E * \mathrm{~F}\right)\right.$

$\left.\left(\left(\mathrm{Vij}^{* *} 2-\mathrm{V}_{\mathrm{ij}} \mathrm{V}_{\mathrm{ii}}\right)^{*}\left(1 / \mathrm{V}_{\mathrm{ij}}{ }^{* *} 2-1\right)\right)\right)$ :

INTER $=($ UPLM - LOUM) $/ 300$; DO \&P2 $=($ LOLM-INTER) TO (UPLM + INTER)
BY INTER;

$\mathrm{A}=\mathrm{V}_{\mathrm{ij}}$

$B=2 * V_{i j} *(\& P 2-\& P 2 \& H A T)$ :

$\mathrm{CC}=\mathrm{Vii}_{\mathrm{ii}}\left((\& \mathrm{P} 2-\& \mathrm{P} 2 \& \mathrm{HAT})^{* *} 2\right)-\left(2^{*} \mathrm{MSE} \mathrm{F}^{*} \mathrm{P}\right)$

$\& P 1=\left(-B+S Q R T\left(\left(B^{* *} 2\right)-4^{*} A * C C\right)\right)$ $\left(2^{*} A\right)+\& P 1 \& H A T$

OUTPUT UPPER;

$\& \mathrm{P} 1=\left(-\mathrm{B}-\mathrm{SQRT}\left(\left(\mathrm{B}^{* *} 2\right)-4^{*} \mathrm{~A}^{*} \mathrm{CC}\right)\right)$

$(2 * A)+\& P 1 \& H A T$

END;

UTPUT

PROC SORT DATA = UPPER

BY \&P2

* SORT TWo halves AND

* REASSEMBLE FOR

* BETTER PLOTTING.

$\bullet$

PROC SORT DATA $=$ LOWER

BY DESCENDING \&P2
GURE RANGE OF CALC

* BASED ON THE DERIV

1* OF THE ELLUPSE $=0$

l* START Elupse CalC's.

* SET Elupse PaRaM'S

- BASED ON THE ELIIPSE

* THE QuAD. Formula. 
DATA PERM. ELI, \&P1\&P2;

* SAVE ELIJPSE ON

* DISK FOR LATER

I* REFERENCE.

DATA ELL;

SET PERM.ELL \&P1\&P2

DATA ANNO

XSYS = '2'; YSYS = '2'; COLOR = 'WHITE';

1* POINT \# (3)

* SET UP ANNOTATE

FUNCTION ='LABEL'; STYLE='COMPLEX'; $1 *$ DATA SET TO PLOT

TEXT $={ }^{\prime}+{ }^{\prime} ;$ POSITTON $={ }^{\prime}{ }^{\prime} ; \mathrm{SIZE}=2 ; \quad 1^{*}$ THE LEAST SQUARES

$\mathrm{X}=1.98 ; \mathrm{Y}=.464$; OUTPUT; $\left.\quad\right|^{*}$ ESTTMATE AS A PLUS

AXIS1 LABEL $=\left(\mathrm{F}=\right.$ COMPLEX $\mathrm{H}=3$ ANGLE $=90^{\circ}$ "\&P1" $)$

VALUE $=(F=$ COMPLEX $H=2.5)$;

AXIS2 LABEL $=(\mathrm{F}=$ COMPLEX $\mathrm{H}=3$ " \&P2"

VALUE $=(\mathrm{F}=$ COMPLEX $\mathrm{H}=2.5)$;

SYMBOL1 I $=$ JOIN V $=$ NONE C $=$ WHITE;

PROC GPLOT DATA $=$ ELL;

PLOT \&P1*\&P $=1 /$ ANNO $=$ ANNO FRAME $\mathrm{VREF}=.3297 . .5983 \mathrm{LV}=20$ $\mathrm{HREF}=1.952,2.007 \mathrm{IH}=20$ VAXIS = AXIS1 HAXIS $=$ AXIS2

\section{1* POINT \# (4)}

* Plot elijpse with

1* APPROPRIATE labels.

* $95 \%$ MARGINAL INTERV

* SET WITH VREF \& HREF.

\section{SAS Codes for Confidence band on Expectation Function, RMS, PRESS, and Residual Plots}

\section{DATA OGERM;}

INFILE 'D:ONREP1. DAT' FIRSTOBS $=5$;

1* RFAD IN DATA

INPUT REP VAR $\$$ TRT X GERM

IF VAR $={ }^{\prime} \mathrm{C}^{\prime}$ AND TRT $=1$.

PROC NIJN METHOD $=$ GAUSS BEST $=1$ DATA $=$ OGERM:

PARMS $M=15 \mathrm{~K}=1.5 \mathrm{~L}=7 \mathrm{C}=.5$.

$\mathrm{TEMP} 1=\mathrm{X}-\mathrm{I}$

* OUTPUT INFo

1* FOR RESIDUAL

* PLOTS, PRESS

TEMP $=\operatorname{EXP}\left(-\left(\left(\mathrm{K}^{*}(\mathrm{TEMP} 1)\right)^{* *} \mathrm{C}\right)\right) ; \quad \quad{ }^{*}$ AND CONFIDENCE

MODEL GERM $=\mathrm{M}^{*}(1$-TEMP);

DER.M $=(1-$ TEMP $)$;

* SET PRED1.

K $=\left(\mathrm{M}^{*} \mathrm{C}\right) *$ TEMP** $\left.\left(\mathrm{K}^{*}(\text { TEMP1 })\right)^{* *}(\mathrm{C}-1)\right)^{*}($ TEMP1)

DER. $\mathrm{L}=\left(-\mathrm{M}^{*} \mathrm{C} * \mathrm{~K}\right) * \mathrm{TEMP}^{*}\left(\left(\mathrm{~K}^{*}(\mathrm{TEMP} 1)\right)^{* *}(\mathrm{C}-1)\right)$;

New Prairie Press

https://newprairiepress.org/agstatconference/1991/proceedings/3
DER.C $=(M) *$ TEMP* $\left(\text { LOG }\left(\left(\mathrm{K}^{*}(\text { TEMP1 } 1)\right)\right)\right)^{*}\left(\mathrm{~K}^{*}(\text { TEMP1 })\right)^{* *} \mathrm{C}$

*/ OUTPUT OUT $=$ PREDI $P=P R \quad R=$ RESID STUDENT $=S$ RESID L95 = LOW U95 =UP H =LEV TITLE1 'FT TO ONION DATA USING WEIBULL',

PROC GPLOT

PLOT GERM ${ }^{*} X$ PR* $^{*}$ /OVERIAY;

* PLOT EXPECTED

PLOT $S$ RESID $* X / V R E F=0$;

* FUNCTION \& DATA

* AND RESIDUALS

* PLOT EXPECTED

PROC GPLOT

PLOT PR*X LOW*X UP*X/OVERIAY;

* FUNCTION AND

* CONFIDENCE BANDS

DATA DIAG;

SET PRED1;

PRESSi $=(\operatorname{RESID} /(1-\mathrm{LEV}))^{* *} 2$

/ CALC. PRESS(i)

* SUM PRESS(i) TO

PROC MEANS SUM

* GET PRESS STAT.

*/

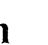




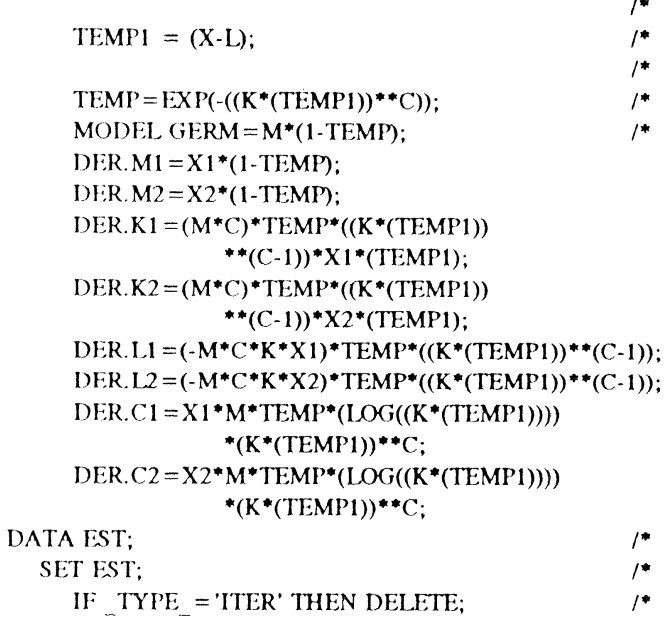

PROC IML;

USE EST:

READ ALL INTO ESTIM

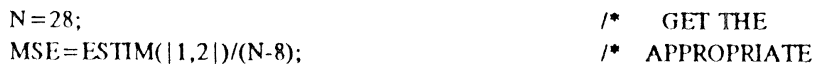

$\mathrm{DPD}=\mathrm{ESTTM}(\mid 2 \cdot \mathrm{NROW}(\mathrm{ESTTM}), 3 \cdot \mathrm{NCOU}$ (ESTTM) $\mid) / \mathrm{SQRT}(\mathrm{MSE}) ; / *$ PIECES.

THETA $=(\text { ESTIM }(\mid 1,3: \text { NCOLESTIM) } \mid))^{\prime}$;

$1 *$

1* WRITE

1* contrasts

$\mathrm{H} 1=\left\{\begin{array}{llllllll}1 & 0 & 0 & 0 & -1 & 0 & 0 & 0\end{array}\right\}$

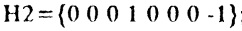

$\mathrm{H} 3=\left\{\begin{array}{llllllll}0 & 1 & 0 & 0 & 0 & -1 & 0 & 0\end{array}\right\}$

$\mathrm{H} 4=\left(\begin{array}{lllllllll}1 & 0 & 0 & 0 & -1 & 0 & 0 & 0\end{array}\right.$

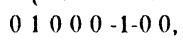

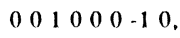

$\begin{array}{lllllllll}0 & 0 & 0 & 1 & 0 & 0 & 0 & -11\end{array}$

1* ORDER IS M1, L1, K1, C1, M2, L2, K2, C2 */

MSR $1=\left(\left(\text { H } 1^{*} \text { THETA }\right)^{*}\right.$ INV $\left(H 1^{*} \text { DPD } * 1^{\prime}\right)^{*}\left(\mathrm{H} 1^{*}\right.$ THETA $) /$ NROW(H1);/CALCULATE THE */ MSR2 $=\left(\left(\mathrm{H}_{2}^{*} \mathrm{THETA}^{*} * \mathrm{INV}\left(\mathrm{H} 2^{*} \mathrm{DPD} * \mathrm{H}^{\prime}\right)^{*}\left(\mathrm{H} 2^{*}\right.\right.\right.$ THETA $) / \mathrm{NROW}(\mathrm{H} 2) \gamma^{*}$ REDUCED MSreg $\mathrm{S} *$ MSR3 $=\left(\left(\mathrm{H}^{*}{ }^{*} \text { THETA }\right)^{*}{ }^{*} \mathrm{INV}\left(\mathrm{H}^{*}{ }^{*} \mathrm{DPD}^{*} \mathrm{H}^{\circ}\right)^{*}\left(\mathrm{H}^{*}{ }^{*}\right.\right.$ THETA $\left.)\right) / \mathrm{NROW}(\mathrm{H} 3) f^{*}$ USING THE MSR4 $=\left(\left(\mathrm{H}^{*} \text { THETA }\right)^{* *} \text { INV }\left(\mathrm{H}^{*}{ }^{*} \mathrm{DPD}^{*} \mathrm{H}^{*}\right)^{*}\left(\mathrm{H}^{*} \text { THETA }\right) / \mathrm{NROW}(\mathrm{H} 4)\right\}^{*}$ GEN LN HYP $*$

$\mathrm{F} 1=\mathrm{MSR} 1 / \mathrm{MSE}$

/*
$\mathrm{F} 2=\mathrm{MSR} 2 / \mathrm{MSE}$

$\mathrm{F} 3=\mathrm{MSR} 3 / \mathrm{MSE}$

$\mathrm{F} 4=\mathrm{MSR} 4 / \mathrm{MSE}$

$\mathrm{P} 1=1-\operatorname{PROBF}(\mathrm{F} 1, \mathrm{NROW}(\mathrm{H} 1), 20)$;

$\mathrm{P} 2=1-\operatorname{PROBF}(\mathrm{F} 2, \mathrm{NROW}(\mathrm{H} 2), 20)$;

$\mathrm{P}=1-\operatorname{PROBF}(\mathrm{F} 3, \operatorname{NROW}(\mathrm{H} 3), 20)$;

$\mathrm{P} 4=1-\operatorname{PROBF}(\mathrm{F} 4, \mathrm{NROW}(\mathrm{H} 4), 20)$ :

PRINT F1 P1,,F2 P2,,F3 P3,,F4 P4;

\section{SAS Codes for Profile $t$ Plots}

WLET MHAT $=85.3$

QLET LHAT $=1.98$;

XIET KHAT $=1.19$

OLET KHAT $=1.19$

\%LET SE $=2.1938$

6 LET SS $=2467.13$;

SLET DF $=116$

\%LET $\mathrm{F}=3.48$;

\&LET T $=0.0$;

* calculate F

STATISTICS

AND

p values.

* PRINT RESUlTS.

* DEFINE MACRO

* VARIABLES FOR

1* USE IN LATER

1* Calculations

$1 *$ THESE ARE

* est.'s from

1* PRIOR NUN RUN

1* F IS A CUT OFF

1* VALUE FOR TAU $=$

1* SQRT(F(P,N-P; $\alpha)$

macro taU(DELT);

DÁTA NULL:

$\mathrm{VAL}=\left(\& \mathrm{DELT}^{*} \& S E\right)+\&$ MHAT;

CALL SYMPUT('MTRY',VAL);

* CONvert the DeL

1* VAlue to THE

* PARAM SCALE

PROC NIIN METHOD $=$ GAUSS BEST $=1$ DATA $=$ OGERM OUTEST $=$ EST

PARMS $M=\& M T R Y ~ K=\&$ KHAT L $=$ \&LHAT C $=\&$ CHAT

BOUNDS \&MTRY $<=\mathrm{M}<=\&$ MTRY $, \mathrm{K}>0,0<\mathrm{L}<3,0<\mathrm{C}<3$;

$$
\text { TEMP1 = X-L; }
$$

TEMP $\left.=\operatorname{EXP}\left(-\left(\left(\mathrm{K}^{*}(\mathrm{TEMP} 1)\right)\right)^{* *} \mathrm{C}\right)\right)$

MODEL GERM $=\mathrm{M}^{*}(1-\mathrm{TEMP})$

DER. $M=(1-$ TEMP $)$;

DER. $\mathrm{K}=\left(\mathrm{M}^{*} \mathrm{C}\right) * \mathrm{TEMP}^{*}(\mathrm{~K} *(\mathrm{TEMP1}))$ $*(\mathrm{C}-1))^{*}(\mathrm{TEMP} 1)$.

DER $\mathrm{L}=\left(-\mathrm{M}^{*} \mathrm{C} * \mathrm{~K}\right) * \mathrm{TEMP}^{*}\left(\left(\mathrm{~K}^{*}(\mathrm{TEMPI})\right)\right.$ $* *(\mathrm{C}-1))$;

DER.C $=(M)^{*}$ TEMP* $\left(\right.$ LOG $\left(\left(K^{*}(\right.\right.$ TEMP1 $\left.\left.\left.)\right)\right)\right)$ ${ }^{*}\left(\mathrm{~K}{ }^{*}(\mathrm{TEMP} 1)\right)^{* *} \mathrm{C}$;

* CONVERGE ON

1* PARAMETERS

$1 *$ WHILE HOLDING

1* ONE CONSTANT

1* (eg M).

1* THIS IS DONE

1* TO Get A VAlue

$1 *$ OF SSE WHICH IS

* USED TO CALC

1* TAU.

1* RETRIEVE DATA

1* SET FROM NUIN

IF TYPE ='FINAL'
$* 1$
$* 1$
$* 1$
$* 1$
$* 1$
$* 1$
$* 1$
$* 1$
$* 1$
$* 1$
$* 1$
$* 1$
$* 1$

$*$

$* 1$
$* 1$
$* 1$
$* 1$
$* 1$
$* 1$
$* !$
$* !$
$* 1$ 
DEL $=\& D E L T ;$

TAU $=\operatorname{SIGN}(\& M T R Y-\& M H A T) *$

SQRT(( SSE - \&SS $) /(\& S S / \& D F))$

TABS = ABS(TAU);

FIE 'A:M.DAT' MOD;

PUT @1 DEL @10 TAU;

* call symput('mhat', m)

CALL SYMPUT('LHAT',L):

CAIL, SYMPUT('KHAT',K);

CALL, SYMPUT('CHAT', C):

CALL SYMPUT('T',TABS):

\%MFND;

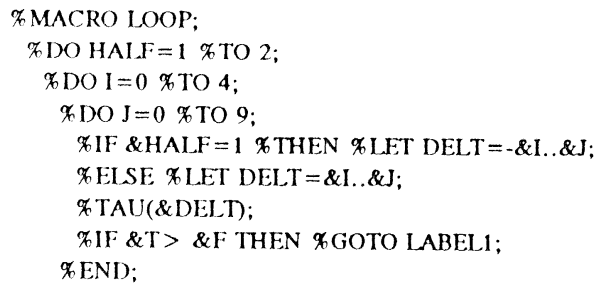

\&IF \&T > \&F THEN \&GOTO LABELI;$$
\text { \&END; }
$$

FLABEL1: \%END:

FEND;

\%MEND;

\section{DATA OGERM:}

INFILE 'A:ONION.DAT' FIRSTOBS $=5$

INPUT REP VAR $\$$ TRT X GERM:

IF $V A R={ }^{\prime} C^{\prime}$ AND TRT $=0$

\%LOOP
* AND CALCUlate

/* Delta AND TaU.

OUTPUT RESUlt

/* TO ASCII Fle.

* UPDATE PARAM'S

/* FOR NEXT ITER.

* ALso abs(tau)

1* FOR TEST W/F

* REPEATEDLY CALL

"* macro 'taUo'

$1 *$ WITH VALUES OF

* Delta, Frst

1* NEGATIVE THEN

1* POSITTVE. THIS

* STOPS IF T > F

** THIS PROCESS

1* IS REPEATED FOR

* ALl parameIters

* tHe macro

* VARIABLE SE

$l^{*}$ (S.E. OF EST)

1* MUST BE SET FOR

* THE PARAMETER

/* BEING WORKED ON

* THIS Parameter

* MUST ALSO BE

\%* BOUNDED BY TRY. 